http://jmscr.igmpublication.org/home/

ISSN (e)-2347-176x ISSN (p) 2455-0450

crossref DOI: https://dx.doi.org/10.18535/jmscr/v7i10.153

Journal Of Medical Science And Clinical Research

IGM Publication

An Official Publication of IGM Publication

\title{
Fine needle aspiration cytology of salivary gland lesions - correlation of cytological diagnosis and histopathological diagnosis
}

\author{
Authors \\ K Sreelatha ${ }^{1}$, S Srikanth ${ }^{2 *}$ \\ ${ }^{1}$ Assistant Professor, Department of Pathology, Prathima Institute of Medical Sciences, Nagunur, \\ Karimnagar, Telangana, India, \\ ${ }^{2}$ Professor, Department of Pathology, Malla Reddy Institute of Medical Sciences, Suraram, \\ Hyderabad, Telangana, India, \\ *Corresponding Author \\ Dr S Srikanth
}

Professor, Department of Pathology, Malla Reddy Institute of Medical Sciences, Suraram, Hyderabad, Telangana, India

\begin{abstract}
Introduction: Although salivary gland tumors account for 2-6.5\% of all head and neck tumors, their superficial location, easy accessibility and high Diagnostic Accuracy makes FNAC a popular method for evaluating salivary gland tumors. Salivary gland tumors can arise from either the major salivary glands (parotid, submandibular and sublingual) or the minor salivary glands which are located throughout the submucosa of the upper aerodigestive tract.

Materials \& Methods: The present study is a prospective study comprising of 62 cases of salivary gland lesions encountered in during 2yrs period. Aspiration was done at the Department of Pathology after a thorough clinical examination of the patient, in each instance. The procedure was repeated in cases where the aspiration was acellular or inconclusive.

Results: Out of total 62 cases of salivary gland lesions in Prathima Institute of Medical Sciences, Karimnagar, 48 cases underwent surgery and were followed by histopathological diagnosis. These 48 cases were considered as the study group for the present study of cytological and histopathological correlation of salivary gland lesions and calculating their diagnostic accuracy. In the present study, parotid gland (40 cases) was the commonest site involved. Submandibular gland, sublingual gland and minor salivary glands were involved in 20cases, 1 case and 1 case respectively.

Conclusion: The main advantage of this procedure is that it can be repeated at different sites in a particular lesion. FNAC is useful as an outpatient diagnostic procedure because of immediate diagnostic results in comparison with the histopathological diagnosis.

Keywords: Salivary glands, Fine needle aspiration, pleomorphic adenoma.
\end{abstract}

\section{Introduction}

Fine Needle Aspiration Cytology (FNAC) of suspected salivary gland lesions has an established role in preoperative diagnosis and management of patients. ${ }^{1}$ The major and minor salivary glands are subjected to developmental, inflammatory, immunopathic, degenerative and neoplastic diseases. Thus, the diseases of salivary gland form an important and yet an interesting group of lesions in respect to their diagnosis, treatment and 
prognosis. A review of the more recent reported series presented in 2013 found that Diagnostic Sensitivity varied between $81-100 \%$, Specificity was $94-100 \%$ and the Accuracy of tumor typing was $90-95 \%$. FNAC of the salivary gland tumors is accurate, simple, rapid, inexpensive, well tolerated and harmless to the patient. ${ }^{2}$

Salivary gland tumors can arise from either the major salivary glands (parotid, submandibular and sublingual) or the minor salivary glands which are located throughout the submucosa of the upper aerodigestive tract. Malignant tumors comprise $15-20 \%$ of all parotid tumors, $37-43 \%$ of submandibular gland tumors and over $80 \%$ of minor salivary gland tumors. ${ }^{3}$

Between $64-80 \%$ of all primary epithelial tumors occur in parotid glands, $7-11 \%$ occur in the submandibular glands, less than $1 \%$ occur in the sublingual glands and $9-23 \%$ occur in the minor glands. In the files of Armed Forces Institute of Pathology (AFIP), about 1/3rd of major gland and half of minor gland tumors are malignant. The ratio of malignant to benign tumor is greatest (>2.3:1) in the sublingual gland, tongue, floor of the mouth and retro-molar area. The mean age at presentation for malignant salivary neoplasms is 55 to 65 years while benign lesions typically develop atleast a decade earlier, at a mean age of 45 years.

\section{Aims and Objectives}

The aim of the present study is to examine the cytological details in aspirated smears from salivary gland swellings and to evaluate the efficacy of Fine needle aspiration cytology in the diagnosis of salivary gland lesions, to study Fine needle aspiration smears from both Non neoplastic $\&$ Neoplastic salivary gland lesions, to conduct histopathological examination of the specimens in operated cases and to correlate cytological and histopathological features and to know the diagnostic accuracy.

\section{Materials \& Methods}

The present study is a prospective study comprising of 62 cases of salivary gland lesions encountered during $2 y r s$ period. Aspiration was done at the Department of Pathology after a thorough clinical examination of the patient, in each instance.

The procedure was repeated in cases where the aspiration was acellular or inconclusive. The written and informed consent is obtained from the patient for the procedure.

The patient is made to take a suitable position on the bed. The nodule of interest is palpated first and then the area is cleaned with $95 \%$ ethanol soaked pads. The swelling is fixed with the thumb and index finger of one hand. With the other hand, 10$20 \mathrm{ml}$ disposable syringe with the 24-22 gauge needle attached to it is introduced through the skin and into the nodule. At this point, 10-20 rapid back and forth strokes are made within the lesion.

Negative pressure is created by withdrawing the plunger, when 2-3 CC of material appears in the needle hub, the aspiration is stopped, and the pressure is released and the needle is withdrawn from the patient. Hemostasis is achieved with the gauze and local pressure. The needle is removed from the syringe, air is drawn into the syringe, the needle reattached and the material is expressed onto a clean glass slide. Smears are gently prepared using a second slide.

For Pap and $\mathrm{H}$ and $\mathrm{E}$ staining, the slides are immediately fixed in Carnoy's fixative $/ 95 \%$ ethanol and the rest of the slides are air dried for MGG staining. All the slides are labelled. In cases of fluid aspiration, slides are made from uncentrifuged and as well as from centrifuged material. Special stains were performed as and when required. The slides were examined under light microscope. Histopathological correlation was done with the FNAC findings whenever possible. Sensitivity, Specificity and Diagnostic Accuracy were calculated with the help of the statistical data.

\section{Results}

Among these, 48 cases underwent surgery and were followed by histopathological diagnosis. 
These 48 cases were considered as the study group for the present study of cytological and histopathological correlation of salivary gland lesions and calculating their diagnostic accuracy. Age of the patients ranged from 18 months to 85 years and the maximum number of lesions were seen in the age group 21-30 yrs (37.09\%), followed by $41-50$ years (16.12\%) (Table No. 1).

Table 1: Age distribution pattern in Salivary gland lesions

\begin{tabular}{|l|c|c|}
\hline Age group & No. of cases & Percentage(\%) \\
\hline $0-10$ & 3 & 4.83 \\
\hline $11-20$ & 8 & 12.90 \\
\hline $21-30$ & $\mathbf{2 3}$ & $\mathbf{3 7 . 0 9}$ \\
\hline $31-40$ & 5 & 8.06 \\
\hline $41-50$ & 10 & 16.12 \\
\hline $51-60$ & 5 & 8.06 \\
\hline $61-70$ & 6 & 9.67 \\
\hline $71-80$ & 1 & 1.61 \\
\hline $81-90$ & 1 & 1.61 \\
\hline Total & 62 & 100 \\
\hline
\end{tabular}

In the present study, a male predilection was seen. Among the 62 cases studied 35 cases $(56.45 \%)$ were males and 27 cases ( $43.54 \%$ ) were females.[ Piediagram 1]

\section{Gender distribution}

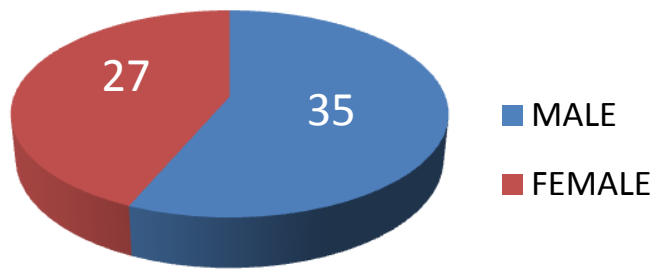

In the present study, parotid gland (40 cases) was the commonest site involved. Submandibular gland, sublingual gland and minor salivary glands were involved in 20cases, 1 case and 1 case respectively.[Table 2]

Table 2: Showing different sites in the present study

\begin{tabular}{|l|c|c|}
\hline Site & No.of cases & Percentage $(\%)$ \\
\hline Parotid & $\mathbf{4 4}$ & $\mathbf{7 0 . 9 6}$ \\
\hline Submandibular & 16 & 25.80 \\
\hline Sublingual & 1 & 1.61 \\
\hline Minor salivary & 1 & 1.61 \\
\hline Total & 62 & 100 \\
\hline
\end{tabular}

In the present study benign lesions are most common constitute about 30 (48.38\%) cases compared to non-neoplastic and malignant lesions constituting $20 \quad(32.25 \%)$ and $12 \quad(19.35 \%)$ respectively.[Table 3]

Table 3: Showing various lesions in the present study

\begin{tabular}{|l|c|}
\hline Lesions & Cytodiagnosis \\
\hline Non-neoplastic & $20(32.25 \%)$ \\
\hline Benign & $\mathbf{3 0}(\mathbf{4 8 . 3 8 \%})$ \\
\hline Malignant & $12(19.35 \%)$ \\
\hline Total & $62(100 \%)$ \\
\hline
\end{tabular}

In the present study cytological and histological diagnosis of non-neoplastic salivary gland lesions 8 cases were correlated out of 10 cases. [Table 4]

Table 4: Correlation of cytological \& histological diagnosis of non-neoplastic salivary gland lesions

\begin{tabular}{|l|c|c|}
\hline \multirow{2}{*}{ Cytodiagnosis } & \multicolumn{2}{|c|}{ Histopathological diagnosis } \\
\cline { 2 - 3 } & $\begin{array}{c}\text { Correlated } \\
(\mathbf{n} \%)\end{array}$ & $\begin{array}{c}\text { Not } \\
\text { correlated } \\
(\mathbf{n} \%)\end{array}$ \\
\hline Chronic siaadenitis & 06 & 02 \\
\hline Mucocele & 02 & - \\
\hline Total & 08 & 02 \\
\hline
\end{tabular}

In the present study cytological and histological diagnosis of neoplastic salivary gland lesions 35 cases were correlated out of 38 cases.[Table 5]

Table 5: Correlation of cytological \& histological diagnosis of neoplastic salivary gland lesions

\begin{tabular}{|l|c|c|}
\hline \multirow{2}{*}{ Cytodignosis } & \multicolumn{2}{|c|}{ Histopathological diagnosis } \\
\cline { 2 - 3 } & $\begin{array}{c}\text { Correlated } \\
(\mathbf{n} \%)\end{array}$ & $\begin{array}{c}\text { Not } \\
\text { correlated } \\
(\mathbf{n} \%)\end{array}$ \\
\hline BENIGN & 23 & 02 \\
\hline $\begin{array}{l}\text { Pleomorphic } \\
\text { adenoma }\end{array}$ & 02 & - \\
\hline Warthins tumor & - & 01 \\
\hline $\begin{array}{l}\text { Basal cell } \\
\text { adenoma }\end{array}$ & 08 & - \\
\hline MALIGNANT & & \multicolumn{1}{|c|}{} \\
\hline $\begin{array}{l}\text { Mucoepidermoid } \\
\text { carcinoma }\end{array}$ & 02 & 03 \\
\hline $\begin{array}{l}\text { Adenoid cystic } \\
\text { carcinoma }\end{array}$ & 35 & - \\
\hline Total &
\end{tabular}




\section{JMSCR Vol||07||Issue||10||Page 891-896||October}

Figure 1: FNAC of Pleomorphic adenoma showing bimodal population of cells against the chondromyxoid background (H\&E, 10x)

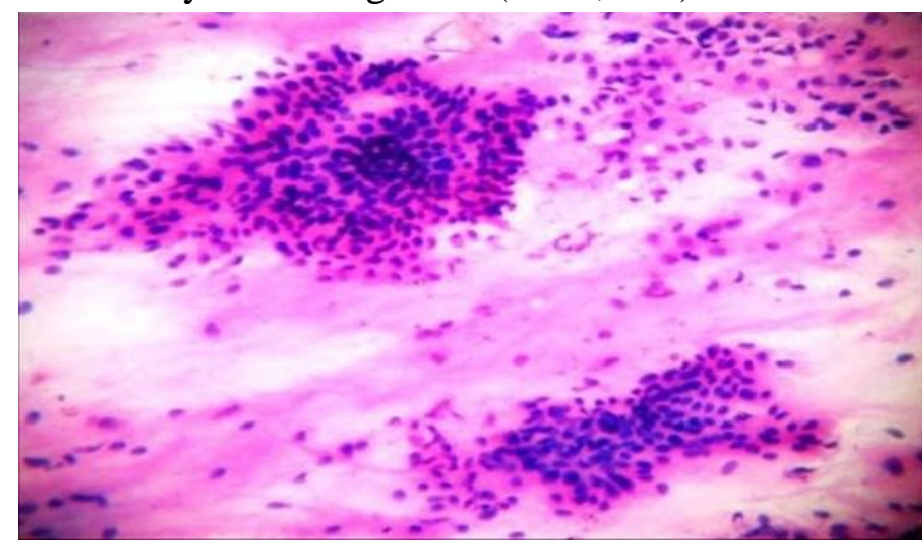

Figure 2: Section studied shows cells arranged in irregular ducts with background showing chondromyxoid (H\&E 40X) - Pleomorphic adenoma.

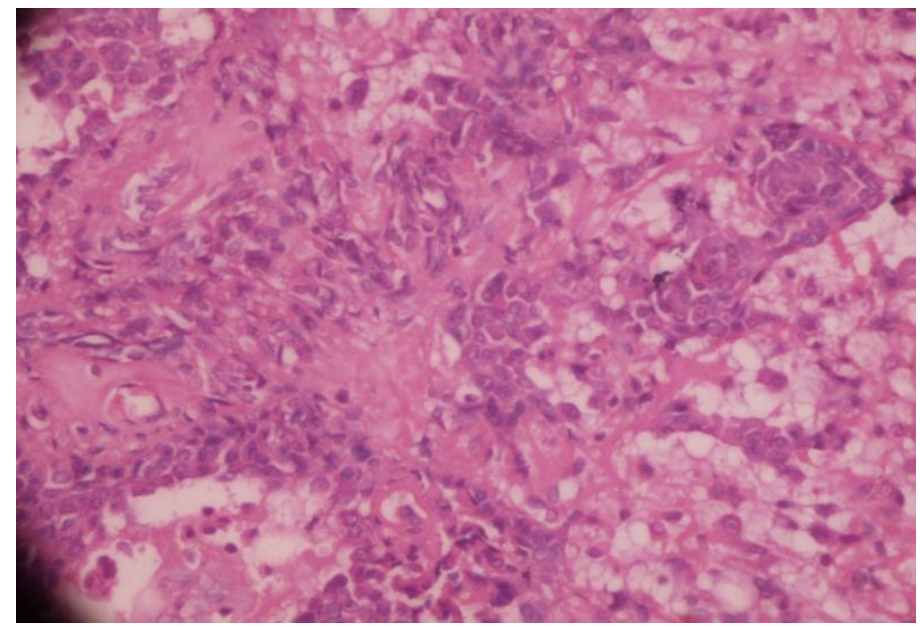

Figure 3: Smears studied showing oncocytic cells in a background of lymphocytes (H\&E, 10x) Warthins tumour

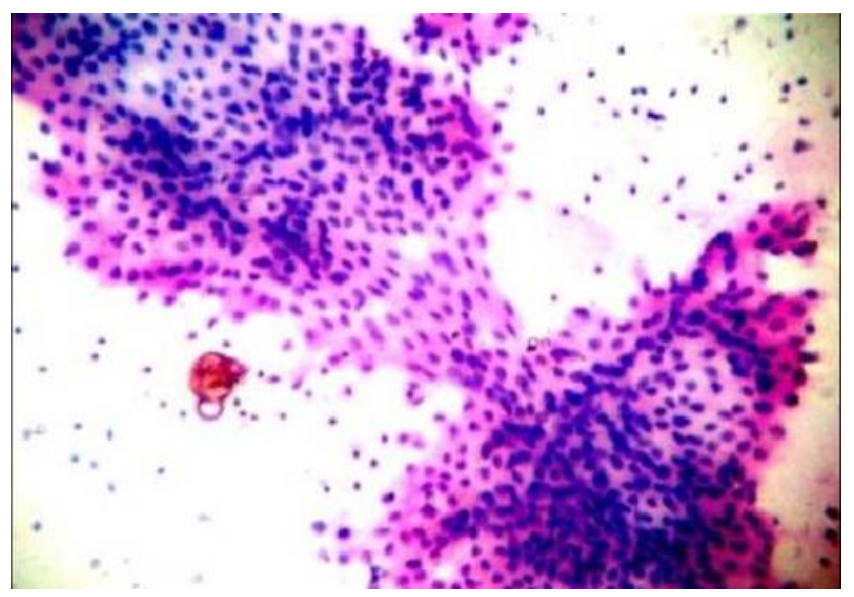

Figure 4: Section studied showing double layer of epithelium with intervening lymphoid aggregates $(\mathrm{H} \& \mathrm{E}, 10 \mathrm{X})-$ Warthins tumour

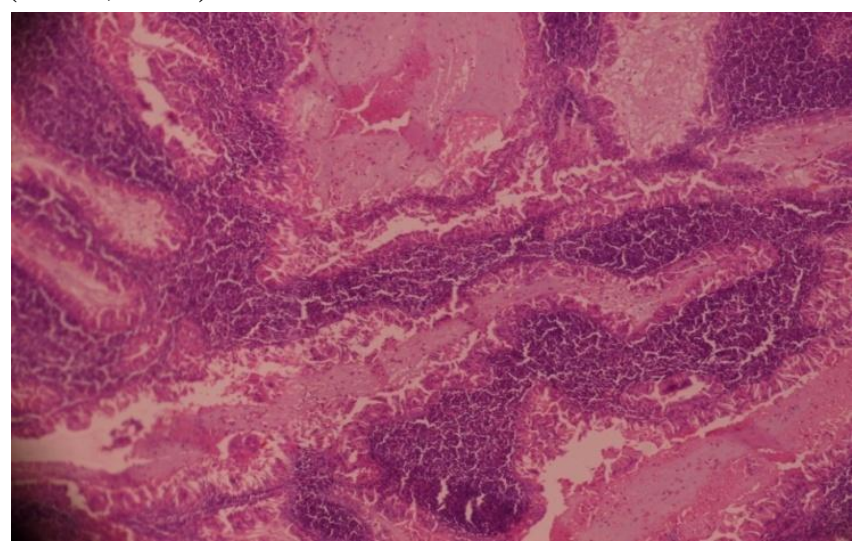

\section{Discussion}

In the present study, 62 aspirations were performed over a period of $2 \mathrm{yrs}$ (October 2011 to September 2013). Out of which 48 cases were followed up by histopathological confirmation. These 48 cases were considered as a study group for the present study of cytological and histopathological correlation of salivary gland lesions and calculating their diagnostic accuracy.

In the present study, salivary gland lesions were common in the 3rd decade, thus involving younger age group as compared to the earlier studies.

FNA cytology provides accurate diagnosis of most salivary gland lesions and contributes to conservative management in many patients with non-neoplastic conditions.

In the present study of 62 cases of salivary gland lesions, 20 cases were non- neoplastic lesions. The non-neoplastic lesions were categorized into inflammatory lesions (17 cases), non-neoplastic cysts (4 cases). As in the study conducted by Akhter J, Hirachand $\mathrm{S}$ and Lakhey $\mathrm{M}^{4}$, inflammatory lesions constituted the majority of non- neoplastic lesions.

Sialadenitis constituted $85 \%$ of all non-neoplastic salivary gland lesions, of which 15 cases (out of 17 cases) were chronic sialadenitis and 2 were acute sialadenitis seen most often in 3rd to 6th decade.

Mixed population of lymphocytes, plasma cells and histiocytes, fibrous tissue fragments, scarcity 
of acinar cells, ductal cell hyperplasia with or without squamous metaplasia were the cytological features of chronic sialadenitis and smears from acute sialadenitis showed predominantly polymorphonuclear leukocytes and necrotic material. Histopathological correlation was available in 8 cases of chronic sialadenitis. Out of 8 cases, 6 cases were correctly diagnosed and 1 case was diagnosed as Mucoepidermoid other as warthins tumor.

On reviewing the smears from the former case it was found that squamoid cells which was misinterpreted as squamous metaplasia of ductal epithelial cells which is a common finding in chronic sialadenitis. This occurs mainly in the submandibular gland (Küttner's tumor) as in this case. Latter case is due to sampling error, in FNAC aspirated only lymphoid component of warthins tumor.

In the present study, out of 20 cases of nonneoplastic lesions there were 3 cases of nonneoplastic cysts. 1 case was Benign Lymphoepithelial Cyst and 2 were mucocoele.

One case of Benign Lymphoepithelial Cysts was seen in submadibular gland and the FNAC slides showed lymphocytes and degenerated epithelial cells against myxoid background.

2 cases of mucocoele were aspirated, the smears of which showed plenty of mucinophages against the mucinous background. 1 of the case was seen in sublingual salivary gland (ranula) and the other was seen in buccal mucosa (minor salivary gland). A ranula is a collection of extravasated mucin from the sublingual glands, it appears as a cyst in the floor of the mouth.

Histopathologically showed cyst like space that is lined by inflammatory granulation tissue. The cyst spaces are filled with mucin as well as inflammatory cells, particularly cyst macrophages. The present study comprised of 37 salivary gland tumors, the findings of which were correlated with other studies. In the present study, ploemorphic adenoma (PA) was the most common tumor accounting for $65.78 \%$ of all tumors and $89.28 \%$ of benign tumors. The peak age incidence was seen in the 3rd decade with a male predominance. The epithelial and mesenchymal like elements were found in wide variety of patterns. Common mesenchymal elements that were seen include fibrous, mucinous, myxochondroid.

Histopathologically epithelial elements resembling ductal cells or myoepithelial cells arranged in ducts, acini, irregular tubules. These elements are dispersed with in a mesenchyme like background of loose myxoid tissue containing islands of chondroid.

Among 27 cases of cytologically diagnosed PA, 25 cases were available for histopathological correlation. 23 cases were concurrently diagnosed in histopathology and one case was diagnosed as Basal Cell Adenoma and other 2 as mucoepidermoid carcinoma. For a cellular Pleomorphic Adenoma, commonest differential diagnosis is Basal Cell Adenoma. It is more of an academic discussion as the management remains the same.

Among 42 cases of salivary gland tumors in the present study, 2 cases were diagnosed as Warthin's tumor on FNAC. 1 was found in the parotid gland and other in submandibular gland and was correlated histopathologically.

In our study, out of 42 cases of salivary gland tumors, there were 10 cases of MEC, which were diagnosed by FNAC. The smears showed 3 types of cells; epidermoid cells, intermediate cells and mucous secreting cells against dirty background. Among the 10 cases of MEC, 8 cases were available for histopathological correlation. All the 8 cases correlated with histopathological diagnosis.

In the present study, 2 cases were seen in the parotid gland. The characteristic diagnostic criteria is the presence of hyaline spherical globules of varying size (basement membrane material) surrounded by tumor cells.

Histopathologically composed of small cells having dark compact nuclei and scant cytoplasm. These cells tend to be disposed in tubular and cribriform pattern. The spaces between cells are filled with a hyaline material thought to represent 
excess basement membrane Both the cases of AdCC correlated with histopathological diagnosis. The Present study is compared with previous studies, Das DK ${ }^{7}$, Ersoz $^{8}$, Akther $^{4}$ correlated cases with various cytological diagnosis. [Table 6]

Table 6: Showing comparision with other studies

\begin{tabular}{|l|c|c|c|c|}
\hline \multirow{2}{*}{ Lesions } & \multicolumn{4}{|c|}{ Cases correlated cytologically $^{-1}$} \\
\cline { 2 - 5 } & $\begin{array}{c}\text { Das D } \\
\mathbf{K}^{\mathbf{5}}\end{array}$ & $\mathbf{E r s o z}^{\mathbf{6}}$ & Akther $^{\mathbf{4}}$ & $\begin{array}{c}\text { Present } \\
\text { study }\end{array}$ \\
\hline Chronic sialadenitis & $2 / 3$ & $18 / 22$ & $2 / 4$ & $6 / 8$ \\
\hline Mucocele & - & - & - & $2 / 2$ \\
\hline Pleomorphic adenoma & $25 / 28$ & $46 / 69$ & $9 / 12$ & $23 / 26$ \\
\hline Warthins tumor & - & - & - & $2 / 2$ \\
\hline $\begin{array}{l}\text { Mucoepidermoid } \\
\text { carcinoma }\end{array}$ & $1 / 2$ & $2 / 16$ & $1 / 1$ & $8 / 8$ \\
\hline Adenoid C C & - & - & - & $2 / 2$ \\
\hline
\end{tabular}

\section{Comparison of diagnostic accuracy of salivary} gland lesions

\begin{tabular}{|l|l|l|l|l|l|l|}
\hline & $\begin{array}{l}\text { Das } \\
\mathbf{D K}^{\mathbf{5}} \\
(\mathbf{n = 4 5})\end{array}$ & $\begin{array}{l}\text { Ersoz }^{\mathbf{6}} \\
(\mathbf{n = 1 5 1})\end{array}$ & $\begin{array}{l}\text { Akther }^{\mathbf{4}} \\
(\mathbf{n = 2 4})\end{array}$ & $\begin{array}{l}\text { Agravat }^{7} \\
(\mathbf{n = 7 8})\end{array}$ & $\begin{array}{l}\text { Jain }^{\mathbf{8}} \\
(\mathbf{n = 8 0})\end{array}$ & $\begin{array}{l}\text { Present } \\
\text { study } \\
(\mathbf{n = 4 8})\end{array}$ \\
\hline Sensitivity & $94.6 \%$ & $94 \%$ & $90 \%$ & $97 \%$ & $92.8 \%$ & $83.3 \%$ \\
\hline Specificity & $75 \%$ & $100 \%$ & $100 \%$ & $80 \%$ & $93.9 \%$ & $100 \%$ \\
\hline $\begin{array}{l}\text { Diagnostic } \\
\text { accuracy }\end{array}$ & $91.1 \%$ & - & $96.43 \%$ & $92 \%$ & $95.83 \%$ & $95.83 \%$ \\
\hline
\end{tabular}

\section{Conclusion}

FNAC of salivary gland tumors is advantageous to both the patient and the clinician because of its immediate results, accuracy, economy and lack of complications. FNAC has high diagnostic accuracy (95.83\% in the present study), which helps in appropriate therapeutic management, whether it is local excision for a benign neoplasm, radical surgery for a malignant neoplasm or alternate treatment.

The main advantage of this procedure is that it can be repeated at different sites in a particular lesion. FNAC is useful as an outpatient diagnostic procedure because of immediate diagnostic results in comparison with the histopathological diagnosis.

\section{References}

1. Kotwal M, Gaikwad S, Patil R, Munshi M, Bobhate S. FNAC of Salivary Gland - A Useful Tool in Preoperative Diagnosis or a Cytopathologist's Riddle? Journal of Cytology 2007;24(2):85-8.
2. Peter Zbaren, Michel Nuyens, Heinz Loosli, Edouard Stauffer. Diagnostic Accuracy of fine needle aspiration cytology and Frozen section in primary parotid carcinoma. Cancer 2004;9(100): 1876-81.

3. Jose Dutra, Steven Battaglia, Robert Kern, Merrill Kies. Salivary gland tumors. Pathology outlines. Com. Salivary glands 6 August 2006, links checked 26 July 2006 copy right (c) 2004-2006, Pathology Outlines.com LLC.

4. Akhter J, Hirachand S, Lakhey M. Role of FNAC in the diagnosis of salivary gland swellings. Kathmandu Univ Med J (KUMJ) 2008 Apr-Jun;6(2):204-8.

5. Das DK, Petkar MA, Al-Mane NM, Sheik ZA, Mallik MK, Anim JT. Role of fine needle aspiration cytology in the diagnosis of swellings in the salivary gland regions: a study of 712 cases. Med Princ Pract 2004 Mar-Apr;13(2):95-106.

6. Ersoz C, Uguz A H, Tuncer U, Soylu L, Kiroglu M Fine needle aspiration cytology of the salivary gland: a twelve years experience : Aegean Pathology Journal 1, 51-56,2004.

7. Agravat AH, Dhruva GA, Pujara KM, Sanghvi HK. Role of Fine Needle Aspiration Cytology in Salivary Gland Pathology and its Histopathological Correlation: A Two Year Prospective Study in Western India. Online J Health Allied Scs. 2012;11(3):5.

8. Jain R, Gupta R, Kudesia M, Singh S. Fine needle aspiration cytology in diagnosis of salivary gland lesions: A study with histologic comparison. CytoJournal 2013;10:5. 